\title{
'Los cuatro estadios', una teoría ilustrada de la evolución social con precedente hispano
}

\section{'The four stages', an illustrated theory of social evolution with Hispanic precedent}

\section{Fermín del Pino Díaz ${ }^{1}$ \\ Centro de Ciencias Humanas y Sociales, CSIC (España)}

ORCID: https://orcid.org/0000-0002-3068-4533

Recibido: 20-01-2021

Aceptado: 25-04-2021

\section{Resumen}

La teoría -especialmente dinámica en la Ilustración escocesa, con A. Smith, J. Millar, A. Ferguson y W. Robertson- de los cuatro estadios (cazadores, ganaderos, agricultores y comerciantes) pasa por ser una historia conjetural con la que se inició la interpretación evolucionista del proceso de la civilización. Se aborda la incidencia en Inglaterra y Francia de la obra del jesuita J. de Acosta (Historia natural y moral de las Indias, Sevilla, 1590) hasta la Ilustración inglesa y escocesa (Locke y Robertson), poniendo especial atención primeramente en la traducción inglesa a cargo de E. Grimstone (1604), a partir de la versión francesa de R. Regnault (1598). Asimismo, se examina con detalle el uso de Acosta en una enciclopedia política francesa muy extendida en Europa (P. D’Avity, 1613),

\footnotetext{
${ }^{1}$ (fermindelpino@gmail.com) Diplomado en Antropología (Centro Iberoamericano de Antropología, 1968), Licenciado y Doctor en Ciencias Políticas (1975). Científico titular del CSIC desde 1981 (Centro de Ciencias Humanas y Sociales), Presidente de la Asociación Madrileña de Antropología (1989-93). Estuvo dirigiendo un equipo desde 1982 a 2013 en el campo de las Crónicas de Indias y la antropología (CSIC). Su campo de estudio es la historia de la Antropología hispana (Crónicas de Indias, expediciones ilustradas, escuela histórico-jurídica de J. Costa, Exilados españoles del 39). Entre sus publicaciones recientes destaca la coordinación (con Ignacio Arellano) del libro Lecturas y Ediciones de Crónicas de Indias (Madrid, Iberoamericana, 2004), Dos mundos, dos culturas, o de la historia (natural y moral) entre España y el Perú. (Madrid, Iberoamericana, 2004), Edición crítica de Acosta: Historia natural y moral de las Indias (Madrid-Lima, CSIC/UNMSM, 2008), Entre textos e imágenes. Representaciones antropológicas de la América indigena. (et al., Madrid, CSIC, 2009), Aprender e instruir en los Andes, siglos XV-XVI, (con Enrique González Carré, Lima, Derrama Magisterial, 2013), El Quadro de historia del Perú (1799), un texto ilustrado del Museo Nacional de Ciencias Naturales (Univ. La Molina, Lima, 2014), y (con Amalia Iniesta) Los mundos diversos del Inca Garcilaso y la academia actual (Universidad la Molina, Lima, 2017).
} 
traducida a varias lenguas, asimismo por Grimstone al inglés. Finalmente se examina los componentes originales de la teoría de los cuatro estadios en Acosta y D'Avity, en sus tres versiones española, francesa e inglesa, como precursores de la teoría antropológica.

Palabras-clave: Acosta, Robertson, Locke, D’Avity, Grimstone, cuatro estadios, evolucionismo, Antropología.

\begin{abstract}
The theory - especially dynamic in the Scottish Enlightenment (A. Smith, J. Millar, A. Ferguson, W. Robertson)- of the four stages (hunters, ranchers, farmers and merchants) happens to be a conjectural history with which the evolutionary interpretation of the process of civilization began. The incidence in England and France of the work of the Jesuit J. de Acosta (Natural and Moral History of the Indies, Seville, 1590) up to the English and Scottish Enlightenment (Locke and Robertson) is addressed, paying special attention first to the English translation by E. Grimstone (1604), based on the French version by R. Regnault (1598). Likewise, the use of Acosta is examined in detail in a French political encyclopedia widespread in Europe (P. D'Avity, 1613), translated into several languages, also by Grimstone into English. Finally, the original components of the theory of the four stages in Acosta and D'Avity are examined, in its three Spanish, French and English versions as precursors of anthropological theory.
\end{abstract}

Keywords: Acosta, Robertson, Locke, D’Avity, Grimstone, four stages, evolutionism, Anthropology.

\title{
1. Los motivos diversos -ahora confesados- de una historia de las teorías
}

Por mi formación inicial en antropología, tiendo a interesarme en autores e ideas que hayan contribuido a la constitución de la disciplina: pero la comunidad antropológica de cada grupo cultural tiende a interesarse más bien en sus propios ancestros, y generalmente en sus maestros. Esa es la conclusión a que llegué cuando hice objeto de mi atención doctoral los manuales introductorios de la disciplina en varias tradiciones occidentales (alemana, francesa, inglesa y norteamericana) ${ }^{2}$. Por esa razón, debo reconocerlo, me ha interesado atender a la historia intelectual de mi disciplina, a cargo de los

${ }^{2}$ Del Pino Díaz, (1975). Sobre la metodología usada, guiada por la autoridad de George Stocking Jr., ver mis dos breves ensayos: Del Pino Díaz (1976) y (1984).

Araucaria. Revista Iberoamericana de Filosofia, Política, Humanidades y Relaciones Internacionales, año $23, \mathrm{n}^{\circ} 47$. Segundo cuatrimestre de 2021. Pp. 111-130. ISSN 1575-6823 e-ISSN 2340-2199 https://dx.doi.org/10.12795/araucaria.2021.i47.06 
jesuitas, particularizando la participación hispana. Los jesuitas tuvieron un aporte relevante en la historiografía misional de las regiones bajo dominio ibérico, así como en la enseñanza humanística universitaria ${ }^{3}$.

En general, los escritos indianos derivados de los jesuistas destacan sobre una amplia literatura, conocida como 'crónicas de Indias' (referida al Nuevo Mundo - las nuevas Indias- y al conjunto asiático/oceánico -las viejas Indias). Aparte su evidente interés literario, es un material documental abundante ${ }^{4}$, apreciado tradicionalmente como fuente temprana de información etnográfica. Lo que escribieron entonces acerca de esas nuevas tierras algunos marinos, médicos, mineros, abogados y otros letrados de los siglos XVI-XVIII que visitaron o se intesaron en estos países indianos (Colón, Cortés, Pizarro, capitán Mena, Cabeza de Vaca, Bernardino de Sahagún, Juan de Tovar, Agustín de Zárate, José de Acosta, André Thevet, Michel de Montaigne, Matteo Ricci, Michele Ruggieri ...) es quizá de lo más valioso que conservamos del largo período colonial europeo. Es opinable la corrección política de la conquista hispana en las Indias, y de hecho fue un campo de Marte para académicos de una u otra procedencia, incluso aún actualmente, pero no es opinable que los actores dejaron una amplia documentación donde abundaba la información puntual -desde ambos lados del encuentro-, y donde había una enorme libertad para la crítica propia y ajena. Pocas conquistas nos legaron tanto patrimonio letrado, tanta materia digna de polémica.

Yo aprendí a apreciar estos testimonios como historia intelectual de maestros y manuales norteamericanos de historia antropológica, como ya lo reconocí en mi tesis doctoral. He privilegiado finalmente la versión norteamericana por motivos interesados, en un doble sentido: porque los documentos hispanos que a mí me interesaban especialmente se ocupaban de gentes que esa otra comunidad nacional considera 'ancestros', de una u otra manera. No se hace un esfuerzo de mirar el pasado, 'a pesar de' nuestro interés presente y grupal, sino 'como corolario' de nuestro egoísmo presentista. En esto creo debemos asumir la teoría política hobbesiana del egoísmo como base originaria de la sociedad ${ }^{5}$, que además se compatibiliza mejor con unos lectores franco-británicos, de que

\footnotetext{
${ }^{3}$ Ver, por ejemplo, la visión panorámica de J. W. O’Malley, S. J. (1995).

4 A nivel comparado, el Archivo General de Indias (Sevilla) es quizás el repositorio colonial más rico actualmente, y no digamos nada si le unimos otros ibéricos más antiguos como el de Simancas (Valladolid), Aragón (Barcelona), Torre do Tombo (Lisboa), o más recientes como el Histórico (Madrid) ...

5 Mucha gente repite el axioma antropológico de Hobbes representado por la frase "homo hominis lupus", como la versión pesimista frente a otros postulados más optimistas y rousseuanianos procedentes de la Escuela de Salamanca y la segunda escolástica. La situación de guerra que refleja, en realidad, obedece realmente a una sensata antropología del egoísmo como principio regulador de la vida social, que asegura la previsibilidad de las conductas individuales para establecer una política adecuada. Por eso fue la línea que terminó triunfando como explicación fundacional, aceptada por pensadores como Groccio, Puffendorf, Locke o Adam Smith. Me he valido de dos ensayos contenidos en A. Pagden (Ed. 1987): el de Istvan Hont, pp. 253-276, y el de Gigliola Rossini, pp. 303-324.
} 
nos ocupamos hoy.

Cierta estima internacional por la literatura hispana de viajes la podemos ver asimismo como una característica singular en el caso de la Ilustración escocesa: me refiero ahora especialmente a la historia americana de W. Robertson (1777), que reconoce desde el principio su base documental en una amplia información americanista procedente de España, donde dispuso especialmente de la ayuda personal del embajador británico Thomas Robinson, junto con la de su capellán, Mr. Waddilove. En 1771, se le envió de embajador británico a España, puesto que retuvo hasta el estallido de la guerra entre ambos países en 1779, por el apoyo español concedido a los rebeldes norteamericanos (se suspende la propia embajada hasta 1783$)^{6}$.

Para ofrecer una noticia puntual de todas las fuentes usadas, el autor incluyó inicialmente un extenso "Catálogo de libros y manuscritos españoles", de una docena de páginas, donde se muestra su considerable erudición hispánica, al mismo tiempo que su propio énfasis documentalista, sello de marca de su procedencia escocesa:

He leido todos estos libros y estos manuscritos con la atención que exige el respeto que un escritor debe tener al público, y he procurado justificar, por medio de citas, la autenticidad de las proposiciones que siento. Cuanto más reflexiono sobre la naturaleza de las obras históricas, tanto más convencido quedo de la necesidad de exactitud. El historiador que refiere los acontecimientos de su tiempo consigue una confianza proporcionada a la opinión que el público tiene de su veracidad y de los medios de que ha usado para instruirse. El que describe los sucesos de una época remota no tiene derecho alguno a la confianza pública si no manifiesta testimonios que apoyen sus aserciones: sin estas autoridades podrá publicar relaciones entretenidas, pero no se dirá que ha escrito una historia auténtica.

\section{La elaboración de un criterio evolutivo de las culturas el Nuevo Mundo. El caso de Acosta}

La obra de Acosta - Historia natural y moral de las indias, Sevilla, 1590 (titulada en adelante H.N.M.I.)- es resultado maduro de una estancia de 14 años del autor como misionero en Perú (1572-86) y de una estancia menor al año en México (1586), donde la Compañía de Jesús español había abierto

\footnotetext{
${ }^{6}$ Durante su embajada (1771-1779), Thomas Robinson trabó amistad con el ministro Ricardo Wall -antiguo diplomático español en Londres, que llegó a primer ministro entre 1757 y 1763, aunque era un militar de origen irlandés- y mantuvieron una interesante correspondencia que ha llegado hasta nuestros días. Este personaje también ejercerá brevemente de Secretario de Estado a su regreso a Inglaterra, y sería esta familia la que protagoniza la historia famosa, llevada a la novela y luego al cine en varias entregas de serie, de la residencia palaciega Downton Abbey, en el condado inglés de Yorkshire, cerca de Londres.
} 
sus primeros colegios (Perú en 1568 y México en 1572). Acosta sería luego autor del primer tratado misional influyente (De promulgando Evangelio apud Barbaros..., Salamanca, 1588), resultado de su reciente experiencia peruanomexicana, pero participando asimismo en el debate de la evangelización en China en su tratado y en actuaciones mediadoras sobre misioneros en China.

La novedad principal de este tratado misional, expresada claramente en su Proemio al lector, es que el misionero debe adaptar su estrategia al nivel cultural de cada pueblo, distinguiendo lo que puede hacerse en el caso de pueblos nómadas y sin autoridad -con los que cabe emplear la fuerza- de los que son propiamente urbanos y sujetos a magistrados y leyes escritas (como es el caso americano de México y Perú, y el asiático de China, la India y Japón), con los que debe emplear la razón y el diálogo.

La historia de Acosta se hacía eco de su propia experiencia personal y misional, pero también de fuentes consagradas previamente, como el jesuita Tovar en México y el abogado Polo en Perú; pero destacaba sobre todas porque se presentaba no como un relato meramente histórico, al uso en estos casos, sino como una interpretación filosófica personal, tanto de los fenómenos naturales como de los etnográficos (llamado aristotélicamente 'historia moral') ${ }^{7}$.

He dedicado específicamente a las traducciones de Acosta cierto tiempo desde mi visita a la British Library de Londres en 1982, con motivo del congreso americanista de Manchester ${ }^{8}$, hasta una muy posterior estancia cuatrimestral como becado en la John Carter Brown Library (doble, en 1993 y 2002). Sólo en la ciudad de Brown -la parte universitaria de la ciudad de Providencehabía varias bibliotecas y de distintos tipos, selectas o masivas: no solo se abría a mis ojos la aristocrática JCBL - tal vez la más completa del mundo en fondos americanos antiguos (sobre todo, europeos) ${ }^{9}-$ sino otras generales de la Universidad, como la multitudinaria Rockefeller Library, donde se podía trabajar desde la madrugada hasta medianoche.

En la British Library ya me había topado a comienzos de los 80 con las primeras traducciones inglesas de la obra de Acosta, descubriendo primeramente -sin pretenderlo- su huella en la propia colección del famoso capellán Richard Hakluyt $^{10}$, y de su sucesor Samuel Purchas, que es conocido por haber ayudado

\footnotetext{
${ }^{7}$ Para una noticia sistemática de esta obra, que ha sido objeto de otros muchos estudios a lo largo del tiempo (entre ellos, varios míos), ver la edición crítica que realicé en 2008, con largo estudio introductorio. Es posible consultarla online digitalizada por la "Fondazione Prospero Intorcetta".

${ }^{8}$ Donde descubrí el famoso libro de Anthony Pagden, en su primera versión de 1982, con quien terminé intercambiando trabajos por mediación del profesor E. Pupo-Walker.

9 Su famoso catálogo ocupa varios tomos: Bibliotheca Americana...1975. Además, por iniciativa de la JCBL se publica una bibliografía muy útil, ordenada cronológicamente (tomo 1, 1492-1600. tomo $2,1600-1650 \ldots)$ que contiene no solamente las deudas de unas obras con otras (1493-1810), en sus diferentes ediciones, sino la ubicación y estado de ejemplares en bibliotecas norteamericanas (170) y europeas (179): John E. Alden and Dennis C. Landis (Eds. 1980-1988).

${ }^{10}$ Entre 1583 y 1588 fue capellán y secretario del embajador inglés en la corte francesa (donde comprará materiales hispano-mexicanos procedentes de André Thevet, cosmógrafo real: por ejemplo
} 
al calvinista holandés Theodor De Bry -expulsado de su Lieja originaria por tropas españolas, y refugiado primero en Estrasburgo y luego en Frankfurt, tras visitar Amberes y Londres- a reunir materiales americanos contra las colonias católicas ${ }^{11}$.

El caso que he estudiado del jesuita Acosta permite diferenciar claramente los usos de Francia e Inglaterra de este tipo de fuentes hispanas de interés etnográfico ${ }^{12}$. Aunque no es el momento de analizar esta obra jesuita, en sí misma, tiene interés esta comparación de su incidencia lectora en Francia durante el s. XVII para entender la reacción de la historiografía ilustrada escocesa, en el siglo siguiente. Teniendo en cuenta que el centro de este proceso divulgador en Europa ocurre en Francia, es un fenómeno que merece estudiarse más, según creo ${ }^{13}$ : en efecto, el francés es la lengua a la que se tradujo más en el primer momento (dando lugar a cinco ediciones en 20 años: 1598, 1600, 1606, 1616 y 1617), lo que significa una amplia difusión entre los lectores.

Pero esta influencia al interior de Francia apenas ha podido ser detectada hasta ahora sino en personajes secundarios: Marc Lescarbot, un intelectual viajero a las colonias francesas en el Nuevo Mundo (Nueva Francia, Acadia); más tarde, en el escritor libertino Isaac La Peyrére (como se verá), y ya muy tardíamente en el jesuita con experiencia canadiense Joseph-François Lafitau (que escribió una obra relevante sobre los iroqueses comparados a los griegos, en 1724, que ha tenido asimismo amplia relevancia intelectual) ${ }^{14}$. Tal vez falta por estudiar incluso la traducción de Robert Regnault, que hizo un elogio magnífico del autor español: "Joseph Acosta, homme certainement docte et fort curieux ... a composée, la plus grand' parte, a veue d'oeil, et sur les mesmes lieux, d'un tel ordre et brieveté, qu'avec bonne raison il peut estre appellé l'Herodote et le Pline de ce monde nouvellement descouvert'. Así, de este modo encomiástico, justificaba el traductor su dedicatoria personal de la obra al rey Henri IV: no damos importancia al hecho mismo de la primera traducción

el Códice Mendoza, adquirido anteriormente de piratas franceses).

${ }^{11}$ Es sorprendente la reiterada influencia francesa en la intelectualidad inglesa por vía diplomática (caso de Hakluyt, de Locke, de Hume, etc. acompañando a embajadores). Los ingleses afrancesados no han tenido que sufrir necesariamente, al parecer, la experiencia del desarraigo para globalizarse.

${ }_{12}$ Para un análisis de la respectiva incidencia en Inglaterra y Francia de libros de viaje hispanos es recomendable ver la tesis doctoral de Jonathan Locke Hart, 1997, luego publicada en Palgrave, 2000. El argumento del autor, según su abstract editorial, es que "Spain was a model to imitate, displace and revile" tanto para la católica Francia como para la protestante Inglaterra, porque eran potencias en competencia. Asimismo, interesan dos recientes tesis ofrecidas online, la de Vincent Gregoire (2017); y la de Madeline H. Grimm (2015). Asimismo, interesa de Daniel Barbu (2014).

13 Apenas conozco sino un solo estudio reciente que tenga en cuenta este proceso en Francia: Dominique de Corcelles, (2003). A fines del s. XX se tradujo por primera vez al japonés (1964), y nuevamente al italiano $(1992,2005)$ y al inglés $(1880,2002,2010)$. Ya no volvió a serlo ni al alemán ni al holandés, que yo sepa, pero volvió a verse traducido dos veces al francés $(1979,1989)$.

${ }^{14}$ Joseph François Lafitau (1724). Su obra ha sido estudiada en conexión con la de Acosta en La caída del hombre natural..., de A. Pagden (en un último capítulo añadido en 1986 a la primera versión de 1982). 
francesa (que se reclama como salvadora del original a punto de perderse) ${ }^{15}$, sino a su reiteración editorial, aunque en algunos ejemplares consultados hoy hemos visto anotada alguna crítica por parte del propietario del ejemplar, sobre la calidad de la traducción ${ }^{16}$.

Lo que nos importa ahora es su eficacia internacional, no solamente nacional: porque, a pesar de la repetida edición a comienzos del s. XVII, no hemos logrado aún percibir su incidencia dentro de Francia. Tal vez haya sido más usada para el problema de los orígenes del hombre americano que para lo que nos interesa en este momento, la conformación de una teoría de la civilización; en este sentido puede consultarse la búsqueda exhaustiva del profesor italiano Giuliano Gliozzi acerca de los logros del pensamiento libertino en Francia, en particular alrededor de Isaac La Peyrére (teórico de la existencia de un hombre pre-adamita, que no necesitase ser redimido del pecado original) y del debate en toda Europa sobre la procedencia externa del homo americanus entre los holandeses de dentro y de fuera, entre Jean de Laet y Hugo Grotius ${ }^{17}$.

\section{La evolución de la teoría de los cuatro estadios en las traduciones europeas de Acosta}

La estrategia propuesta por Acosta para interpretar la historia de los pueblos americanos era diferente, según se tratase de un asunto bíblico o no. Evidentemente, en lo que respecta a interpretar el origen de la humanidad americana no podía hacer caso a las tradiciones míticas indianas, que afirmaban haberse originado desde el principio en tierra americana:

Haciendo yo diligencia para entender de ellos de qué tierras y de qué gente pasaron a la tierra en que viven, hallelos tan lejos de dar razón de esto que antes

15 'Et ce qui plus m'incitait de l'entreprenddre, a esté que les Espagnols, ialoux et enuieux de ce bien, ayants fait brusler par Edict public (comme on m'a adverty puis quelque temps) tous les exemplaires de ceste histoire, a fin d'en priver les autres nations, et leur celer la cognoissance des Indes; i'ay pensé que ie fesrois faute si ie laissois perdre à la France (si curieuse des choses rares et belles) un si riche ioyau, et un si gentille histoire" (cursivas añadidas). He visto en varios diccionarios franceses justificar esta 'boutade' del traductor Regnault, como medio normal de crecer el mérito propio, e incluso llega a creerlo verdad como hecho un historiador de la geografía como Numa Broc (1986).

${ }^{16}$ Del ejemplar conservado en la Bibliotèque nationale de la primera edición de 1598 , sabemos por Dominique de Courcelles que una mano anónima anotó en algún punto (cote G-1818) del ejemplar conservado: "Le traducteur n'a pas bien entendu tous les mots castillans qu'il a trouvés dans l'original". Por lo que hace a la segunda edición de 1600, conservada en la JCBL leemos de manos de un lector italiano: "Questo traduttore in molte cose ha svagliato", poniendo varios ejemplos de vocablos mal entendidos ('gaster le trésor' -y no 'employer' o 'dependre'- por gastar; o 'polaique' - y no 'polaire'- confundiendo polar con polaco).

17 G. Gliozzi (1977). Existe una versión francesa de 2000, Theetete Eds. Gliozzi dedica gran atención al P. Acosta, en su parte III, aunque le importa más la correlación entre la utilización bíblica o paleontológica por Acosta y los intereses coloniales.

Araucaria. Revista Iberoamericana de Filosofia, Política, Humanidades y Relaciones Internacionales, año $23, \mathrm{n}^{\circ} 47$. Segundo cuatrimestre de 2021. Pp. 111-130. ISSN 1575-6823 e-ISSN 2340-2199 https:/dx.doi.org/10.12795/araucaria.2021.i47.06 
tenían por muy llano que ellos habían sido criados desde su primer origen en el mismo Nuevo Orbe donde habitan: a los cuales desengañamos con nuestra Fe, que nos enseña que todos los hombres proceden de un mismo hombre ${ }^{18}$.

Como la Biblia establecía un origen común antes del diluvio universal, el jesuita proponía buscar el origen en el Viejo Mundo, y sugerir que habían llegado a tierras americanas posteriormente, seguramente por vía terrestre (que se sospechaba, por conjetura, que había sido por el norte o por el sur). Sin embargo, sí eran válidas las tradiciones mexicanas y peruanas sobre sus tiempos antiguos - ñupa pacha, que decían los incas: antiguamente- para imaginar cómo se había producido la evolución del Viejo Mundo en tiempos antiguos, mutatis mutandis. Eso es lo que propuso Acosta al final del libro I, y en otros capítulos de la historia moral (es decir, en los libros VI y VII, donde se hace historia política respectiva del Perú y México antiguos). Basta recordar a este respecto la frase que tomó de él Locke sobre los orígenes 'naturales' de las sociedades andinas, antes del gobierno incaico, ampliando un poco la cita:

102. Tendrá que dar muestras de una extraña inclinación a negar la evidencia de los hechos quien, al no concordar con sus hipótesis, no se avenga a reconocer que Roma y Venecia empezaron al conjuntarse cierto número de hombres libres, e independientemente unos de otros, y entre los que no existía superioridad natural o sometimiento. Y, si José de Acosta merece crédito, él nos asegura que en muchas partes de América no existía ninguna clase de gobierno: "Existen claras y notables conjeturas de que aquellos hombres (se refiere a los habitantes del Perú) no tuvieron por espacio de mucho tiempo reyes ni estados, sino que vivían en grupos, tal como hoy mismo hacen en Florida, los cheriquanas, los del Brasil y otras muchas naciones que con toda seguridad no tienen reyes y que, cuando se les ofrece la oportunidad, en tiempo de guerra o de paz, eligen a su gusto los capitanes ${ }^{19}$. [Y añadimos a Locke lo siguiente de Acosta en ese mismo texto, que no citó] "Mas, con el tiempo, algunos hombres que en sus fuerzas y habilidad se aventajaban a los demás comenzaron a señorear y mandar como antiguamente Nembrot-, y poco a poco creciendo vinieron a fundar los reinos de Pirú y de México que nuestros españoles hallaron: que, aunque eran bárbaros, pero hacían grandísima ventaja a los demás indios. Así que la razón dicha persuade que se haya multiplicado y procedido el linaje de los indios por la mayor parte de hombres salvajes y fugitivos" ${ }^{20}$.

18 1590, Libro I, capítulo 25.

${ }^{19}$ Cita perteneciente al capítulo VIII -titulado "Del comienzo de las sociedades políticas"- de su segundo Ensayo sobre el Gobierno Civil (1690). Tomado de la traducción española del mismo, en Madrid: Aguilar, S. A. de Eds., 1977, 2a impr. p. 77. El original de Acosta decía: "Hay conjeturas muy claras que por gran tiempo no tuvieron estos hombres reyes ni república concertada, sino que vivían por «behetrías», como agora los floridos y los chiriguanaes y los brasiles; y otras naciones muchas que no tienen ciertos reyes, sino conforme a la ocasión que se ofrece en guerra o paz eligen sus caudillos, como se les antoja". Tomado de nuestra edición (Acosta 2008).

20 1590, Libro I, capítulo 25, cursivas nuestras. Quiero mostrar así en vivo el proceso como el autor combina datos tomados de fuente variada (indiana y bíblica), para conjeturar un origen y un proceso 
Tenemos aquí algunos elementos que van a estar presentes a partir de entonces en todos los planteamientos de la llamada 'historia conjetural' de los cuatro estadios, aunque pasa por haberse engendrado en la Ilustración escocesa $\mathrm{y}$, particularmente, en las indagaciones americanistas de Robertson. Veamos lo que comparten Acosta y Robertson a este respecto para delimitar un poco la discusión sobre el origen y sobre las características y argumentos de la teoría así llamada.

(A) Por un lado, se juega con las historias de la antigüedad puestas a nuestra disposición (en el s. XVI sobre todo bíblicas, en las que se suponía una limitada antigüedad de unos 4000 años), a las que se somete a la 'falsación' de probabilidades fácticas disponibles (situación de tierras conocidas vecinas al Nuevo Mundo, viajes por mar improbables, nivel cultural comparado de aquellos pueblos, parecidos entre estos pueblos del Viejo y del Nuevo Mundo...). En el caso concreto de la historia bíblica, por ejemplo, Acosta no solamente recoge el tema del origen adánico, sino que -de modo estratégicotoma el caso del héroe Nembrot, famoso rey cazador y descendiente rebelde de Noé, para 'generalizar' el modo en que un pueblo pasa de un estadio a otro ("sus fuerzas y habilidad").

(B) Por otro, ante la ausencia de datos sobre estadios tempranos del Viejo Mundo (antes de la escritura, de la propiedad, la agricultura, la ciudad...), se usan para su reconstrucción los datos de los pueblos americanos, a los que providencialmente - en sentidos varios- los europeos los hallan a primera vista en 'grados' diversos de desarrollo histórico ${ }^{21}$. Estos pueblos tenían sus propias 'historias míticas' con relación a su pasado, que las crónicas de Indias -y, en particular, el P. Acosta- recogen y usan para establecer una relación sistemática de 'sucesión' temporal.

(C) La suma de noticias etnográficas reunidas sobre estos pueblos diferentes de Europa (sea de la antigüedad del Viejo Mundo o del Nuevo), se someten a una 'tipología' de modo que podamos jugar ya con casos-tipos válidos para ser generalizados, con los cuales poder definir cuándo se trata de un estadio diferente, o de una mera variante del estadio-tipo. Así, por ejemplo, el estatuto de canibal ${ }^{22}$-primer ejemplo del salvajismo inicial de todos los pueblos- se construye como algo generalizable a partir de la

evolutivo 'racional'. Lo que sus lectores llamaban un relato conjetural o 'filosófico'.

${ }^{21}$ El momento inicial de esta súbita percepción hispana, y europea, tiene lugar a partir de las primeras noticias del mundo americano continental (Valle de Mexico, dominado por un gran señor, rodeado de cortesanos) que inmediatamente comparan los españoles con el ya conocido mundo isleño y antillano, gobernado por caciques locales (caribes y arawacos). Ya Cortés pondera en sus cartas al emperador la nueva calidad cultural de sus nuevos súbditos.

${ }_{22}$ Palabra derivada de 'caribe', pueblo antillano diferente a sus vecinos los arawacos, que eran pueblos pacíficos vecinos sobre los cuales ejercieron el canibalismo. Canibal dice el DRAE que deriva de 'caribal', por cambio de una por otra letra (r-n). Skakespeare operó un cambio parecido al llamar 'Caliban' al caníbal de su obra La Tempestad (1611), término ('Cannibale') que se encuentra ya desde 1580 en los Ensayos de Montaigne (libro I, cap. 31). 
etnografía particular de este pueblo concreto, descrito por varios cronistas de Indias, desde el mismo Colón. El segundo estadio, el de 'bárbaro', es tomado de la imagen estereotipada que los griegos y romanos se hicieron de sus vecinos persas, invasores periódicos: el término 'bár-baro' -como su derivado 'ber-eber', o como otro posterior de origen holandés para los africanos del sur, 'hoten-tote' - nos indica de modo onomatopéyico una 'foraneidad' lingüística, porque estos pueblos tartamudean al pronunciar palabras de nuestra lengua.

(D) Finalmente, el criterio taxonómico para definir un estadio debe basarse en determinados parámetros institucionales o materiales (religión, economía, política, vivienda, alimento, vestido...). Al definir el paso de un estadio determinado a otro (salvaje, bárbaro, civilizado; y cada uno de ellos dividido en inferior, medio o superior), se supone que se modifican simultáneamente cada uno de estos otros parámetros elegidos: al mudar un pueblo de religión se produce un cambio simultáneo en los otros campos. Es lo que solemos llamar una 'variación concomitante', o simultánea, con un término usualmente sociológico (Stuart Mill, Emile Durkheim, etc.)

En el caso de Acosta, que toma el modelo de la propia historia mítica mexicana elaborada sobre sus propios antepasados, la definición del estadio primero de salvaje se define de este modo tentativo: usando el caso de una genealogía propia -en su caso, las sociedades mexicanas antiguas, descritas por los mexicanos actuales- le sirven para proponer una secuencia general. Debo aclarar que Acosta residió 10 meses en México (desde julio del 86 a mayo del 87) antes de regresar a España, y esa estancia, aunque breve, le fue muy útil para madurar su obra histórica ya iniciada en Perú, de modo que su historia indiana es en gran parte el resultado final de una comparación de la sociedad peruana y la mexicana. Gracias al sistema mexicano de escritura jeroglífica, inexistente en el caso peruano, pudo emplear datos etnográficos de un virreinato para comprender mejor al otro. Véase un párrafo interesante en que muestra cómo opera su procedimiento generalizador:

Los antiguos y primeros moradores de las provincias que llamamos Nueva España fueron hombres muy bárbaros y silvestres que sólo se mantenían de caza, y por eso les pusieron nombre de chichimécas. No sembraban ni cultivaban la tierra ni vivían juntos, porque todo su ejercicio y vida era cazar, y en esto eran diestrísimos. Habitaban en los riscos y más ásperos lugares de las montañas viviendo bestialmente sin ninguna policía, desnudos totalmente. Cazaban venados, liebres, conejos, comadrejas, topos, gatos monteses, pájaros y aún inmundicias como culebras, lagartos, ratones, langostas y gusanos: y desto y de hierbas y raíces se sustentaban. Dormían por los montes en las cuevas y entre las matas. Las mujeres iban con los maridos a los mismos ejercicios de caza 
dejando a los hijuelos colgados de una rama de un árbol, metidos en una cestilla de juncos bien hartos de leche hasta que volvían con la caza. No tenían superior ni le reconocían, ni adoraban dioses ni tenían ritos ni religión alguna. Hoy día hay en la Nueva España d'este género de gente, que viven de su arco y flechas y son muy perjudiciales, porque para hacer mal y saltear se acaudillan y juntan, y no han podido los españoles por bien ni mal, por maña ni fuerza, reducirlos a policía y obediencia: porque, como no tienen pueblos ni asiento, el pelear con éstos es puramente montear fieras, que se esparcen y esconden por lo más áspero y encubierto de la sierra. Tal es el modo de vivir de muchas provincias hoy día en diversas partes de Indias.

Quieren decir que destos mismos eran los que en la Nueva España llaman otomíes, que comúnmente son indios pobres y poblados en tierra áspera; pero están (p. 454) poblados y viven juntos y tienen alguna policía, y aún para las cosas de cristiandad los que bien se entienden con ellos no los hallan menos idóneos y hábiles que a los otros, que son más ricos y tenidos por más políticos. Viniendo al propósito, estos chichimécas y otomíes - de quien se ha dicho que eran los primeros moradores de la Nueva España-, como no cogían ni sembraban dejaron la mejor tierra y más fértil sin poblarla, y ésa ocuparon las naciones que vinieron de fuera que, por ser gente política, la llaman nauatláca -que quiere decir «gente que se explica y habla claro»-, a diferencia de esotra bárbara y sin razón ${ }^{23}$.

Un detalle estratégico que ha sido señalado con frecuencia en esta definición de los estadios es el valor trascendental del nivel económico. El profesor Meek (R. Meek, 1976) enfatizaba por este detalle el componente premarxiano de la teoría de los cuatro estadios. En el caso de Robertson es verdad que este principio queda claramente afirmado: "In every enquiry concerning the operations of men when united together in society, the first object of attention should be their mode of subsistence" (1840, libro IV, p. 86). A este respecto, debo decir que algunos precursores de los siglos XVI y XVII eran ya conscientes de la relevancia del factor económico, aunque pudiera pensarse que otras veces dan prioridad al político o al religioso. Veamos cómo resuelve el asunto Acosta, al ocuparse de otros pueblos en general en el libro anterior "Del gobierno y reyes que tuvieron":

[...] muchas naciones y gentes de indios no sufren reyes ni señores absolutos sino viven en behetría, y solamente para ciertas cosas -mayormente de guerracrían capitanes y príncipes a los cuales durante aquel ministerio obedecen, y después se vuelven a sus primeros oficios. D'esta suerte se gobierna la mayor parte d'este Nuevo Orbe, donde no hay reinos fundados ni repúblicas establecidas ni príncipes o reyes perpetuos y conocidos, aunque hay algunos señores y principales que son como caballeros, aventajados al vulgo de los

${ }^{23}$ Libro VII, cap. 2: "De los antiguos moradores de la Nueva España, y cómo vinieron a ella los nauatlácas". 
demás. D'esta suerte pasa en toda la tierra de Chile, donde tantos años se han sustentado contra españoles los araucanos y Méjico y los de Tucapel, y otros. Así fue todo lo del Nuevo Reino de Granada [Colombia], y lo de Guatemala y las islas, y toda la Florida y el Brasil, y Luzón [Filipinas] y otras tierras grandísimas $[\ldots]$.

En la India Oriental hay reinos amplios y muy fundados, como (p. 415) el de Siam y el de Bisnaga y otros, que juntan ciento y doscientos mil hombres en campo, cuando quieren; y sobre todo es la grandeza y poder del reino de la China, cuyos reyes -según ellos refieren- han durado más de dos mil años, por el gran gobierno que tienen. En la India Occidental solamente se han descubierto dos reinos o imperios fundados, que es el de los mexicanos en la Nueva España y el de los ingas en el Perú: y no sabría yo decir fácilmente cuál déstos haya sido más poderoso reino. Porque en edificios y grandeza de corte excedía el Motezuma a los del Perú. En tesoros y riqueza y grandeza de provincias excedían los ingas a los de México. En antigüedad era más antiguo el reino de los ingas, aunque no mucho; en hechos de armas y victorias paréceme haber sido iguales.

Una cosa es cierta: que en buen orden y policía hicieron estos dos reinos gran ventaja a todos los demás señoríos de indios que se han descubierto en aquel Nuevo Mundo, como en poder y riqueza -y mucho más en superstición y culto de sus ídolos- la hicieron. (VI: 11, cursivas añadidas) ${ }^{24}$.

En el ámbito de los filósofos ilustrados, en general (Buffon, De Paw, Raynal, Robertson...), parece que no se le quiso conceder ese estatuto "político'25. En todo caso, a pesar de no coincidir con el criterio de las crónicas de Indias en su alto concepto de los pueblos de México y Perú, y en especial con el P. Acosta, tiene un alto concepto de esta fuente, de la que tiene dos ejemplares, la versión francesa de 1600 y la inglesa de 1604 , obra de Eward Grimstone: "The natural and moral history of the New World, by the Jesuit Acosta, contains more accurate observations, perhaps, and more sound science, than are to be found in any description of remote countries published in the sixteenth century" 26 .

${ }^{24}$ El profesor Varella $(2014$, n. 8) ha recogido esta referencia de Acosta, que nosotros señalamos como prueba de una variación concomitante entre religión, gobierno y riqueza, pero él la cree limitada por la creencia de Acosta en el poder diabólico: "Tal avaliação é equivalente à trazida pela influente Historia natural y moral de las Indias: as mais bárbaras práticas supersticiosas casavam com as mais avançadas formas de governo entre mexicanos e peruanos (Acosta, 1962, p. 65). No entanto, vale a advertência de que a superstição para Acosta continha uma grande dimensão diabólica, o que deixa de ter sentido para o pensamento cético ilu-minista de Robertson..." (p. 256-b, cursivas añadidas).

${ }^{25}$ He tratado este tema en un ensayo inédito, titulado The Trace of José de Acosta...

${ }^{26}$ W. Robertson, Book VII, "Character of ecclesiastics in Spanish America... the regular", p. 363. 


\section{Precedentes de la admiración ilustrada hacia la historiografía indiana de Acosta}

La traducción inglesa estuvo a cargo de Edward Grimstone, que había traducido otras fuentes españolas ${ }^{27}$ después de traducir a Acosta, pero en todos los casos lo hacía a través de una versión francesa previa: por eso firmará su traducción solamente con sus iniciales (E.G.), y por eso imita el título del traductor francés, único así conocido ${ }^{28}$. Sin embargo, considero que el esfuerzo traductor de Grimstone fue mayor cuando acometió la traducción de una colección de descripciones políticas de todo el mundo conocido, tomada de un autor francés nuevamente, Pierre d'Avity, en que se vuelve a usar la obra de Acosta. Porque en este caso se trataba de abordar no solamente el Nuevo Mundo sino todo el espacio global conocido, dentro del cual la monarquía ibérica se llevó la parte más extensa.

En esa enciclopedia político-moral, el papel principal lo tiene España porque a su descripción se le une el Nuevo Mundo, así como Portugal y sus respectivas colonias en África y Asia $^{29}$. Tiene una serie de capítulos finales que podrían llamarse de 'historia natural y moral', en que utiliza frecuentemente la obra de Acosta cuando trata "Of the diversities of barbarous people, and of the manner of preachinf the Gospell" (1615, pp. 266-270). Yo me atrevería a sostener que la primera expresión de la "teoría de los cuatro estadios" (atribuida generalmente al entorno escocés, como ya lo dio a entender un poco vagamente su estudioso Ronald Meek $)^{30}$ se expone aquí ya de un modo u otro, cuando Grimstone intenta dar razón de la diversidad de pueblos americanos, tanto en base a su economía como su política y su religiosidad.

Nosotros elegimos solamente la parte en que D'Avity (seguramente familiarizado ya con Acosta, traducido por R. Regnault hacía pocos años) se hace eco de sus tesis en cuanto a la clasificación cultural de las sociedades americanas, desde el salvaje al civilizado, pasando por el bárbaro: en lo cual coincide plenamente y le sigue casi literalmente. Se trata ahora de la sección

\footnotetext{
27 The Generall Historie of Spaine, 1609; The Imperial History from the First Foundation of the Roman Monarchy to this Present Time, de Pedro de Mexía, 1623, etc.

${ }_{28}$ Acosta "The natural and morall historie of the East and West Indies", 1604; del mismo modo que “Histoire naturelle et moralle des Indes tant orientales qu'occidentales', 1598.

${ }^{29}$ En la versión inglesa de 1615, tamaño folio, la parte española ocupa de la p. 102 a la 283 (copia de la francesa: donde ocupa de la 132 a la 334, tal vez por el menor tamaño de la página). Una comparación entre la version original francesa de P. D’Avity y la inglesa de su traductor inglés Grimstone ha sido abordada por Joanathan L. Hart, op. cit. 2000 (n. 24). Él contempla el lado del catolicismo coincidente del francés con España, que no tenía el inglés: "The writers in France could frequently be more generous toward Spain than the English were. Often, but not always, this generosity stemmed from a shared Catholicism... the English version was not 'a meere translation' but differed from the author in places where Grimstone had more experience, where there were omissions, and in religious matters" (2000, p. 182).

${ }^{30} \mathrm{R}$, Meek (1976). Ver especialmente su cap. II, "En el principio todo el mundo era América", especialmente pp. 42-49, donde se considera la posible influencia de la obra de Acosta.
} 
final de la parte dedicada a España, en que se ocupa del Nuevo Mundo y concluye con un "Discours en general sur le Nouveau Monde" (pp. 297325), centrado especialmente en temas religiosos. Me refiero en particular al apartado penúltimo, que se ocupa "De la diversité des barbares et de la façon de prescher l'Evangile"31. Deducimos lógicamente que D'Avity -de quien copia Grimstone este capítulo sobre los bárbaros americanos- ha leído además otros textos hispanos para conformar su doble centenar de páginas "De l'estat du Roy d'Espagne" 32 .

En esencia, lo que propone el autor finalmente es similar a la propuesta clasificatoria de Acosta al inicio de su tratado misional ${ }^{33}$, que luego transforma en su Historia de las Indias en una secuencia evolutiva que va del salvajismo a la civilización ${ }^{34}$. D'Avity parte de una definición de la barbarie, para luego aplicarla al Nuevo Mundo: "Les escrivains donnent le nom de barbares aux peuples dont les moeurs s'eloignent de la raison et de la commune façon de vivre" (1613: 317). Está citando al P. Acosta casi literalmente, cuando escribía en latín: "Barbaros autem probati auctores eos esse definiunt, qui recta ratione et hominum communi consuetudine abhorrent". Pero, a su vez, Acosta citará a Sto. Tomás, cuando comenta las epístolas de S. Pablo: "Dicitur autem aliquis barbarus... qui scilicet est extraneus a communitate hominum, in quantum ratione non regitur" ${ }^{\prime 3}$. Es curioso que diga P. d'Avity a continuación, y por su cuenta, que los griegos y romanos merecen más el nombre porque "ont vescu autrement que tout le reste", lo que vacía de sentido el axioma tomista, ligando lo normal a lo racional.

Pero lo más interesante viene a continuación, cuando propone que "la

31 Ocupa las pp. 318-323 en la edición francesa original de 1613, y las 327-330 en la de 1621. En la versión inglesa de 1615 son las p. 266-269 ("Of the Diversitie of Barbarous people, and of the manners of preaching the Gospell”. Este apartado ha sido atendido parcialmente en Olive Dickason (1977). Pueden consultarse las diversas versiones digitalizadas en la Bayerische Staatsbibliothek (de Munchen, Alemania), y la Österreichische Nationalbibliothek, de Austria.

https://www.digitale-sammlungen.de/index.html? $c=$ autoren_index\&ab $=$ Avity $\% 2 C$

${ }^{32}$ Las 202 pp. dedicadas a España forman la parte del león en un libro general que ocupa unas 1500 pp., añadiendo a las 1396 pp. originales un "Discours de l'origine de tous les religions qui jusques à present on esté au monde...", con otras 76 pp. En ediciones sucesivas fueron aumentando las pp., con novedades posteriores.

${ }_{33} \mathrm{Ni}$ en la versión francesa ni en la inglesa se alude al P. Acosta, pero su procedencia resulta evidente, como podremos ver. Tampoco apreciamos bibliografía especial o referencia puntual alguna en otras partes de la obra. Sin embargo, que estas páginas sobre "la diversité des barbares et de la façon de prescher l'Evangile" vengan como corolario final del apartado dedicado a España, sugiere esta conexión bibliográfica. Yo descubrí la versión inglesa de Grimstone en la British Library antes que el original francés de D'Avity, lo que me facilitó asociar esta parte a Acosta como fuente, por tratarse del mismo traductor de Acosta.

${ }^{34}$ Esta propuesta evolucionista fue uno de los temas que abordé primero en mi estudio de Acosta. Ver Del Pino Díaz (1978). Otro ensayo complementario al respecto fue entonces, Del Pino Díaz (1979).

${ }^{35}$ Las citas de ambos y su traducción se hallan en la edición del tratado misional de Acosta por Luciano Pereña et al., 1984, p. 60. En la p. 61 da su traducción: "Según la definición de prestigiosos autores, bárbaros son aquellos que se apartan de la recta razón y de la práctica habitual de los hombres". 
fierté est un certaine brutalité qui a quatre degrez" (idem, cursiva añadida). Esta cuatripartición la entiende de una doble manera: por un lado, como era de esperar, en términos habituales de grados de perfección (cazador, pastor, agricultor y comerciante). Pero, por otro lado (y creo es lo original de este autor) lo divide en términos de criterios, con arreglo a los cuales se mide esa perfección moral de los pueblos (es decir, por la religión, el alimento, el vestido y la habitación). A los cuales cuatro agrega a continuación otros dos criterios, sumamente interesantes (el gobierno y la economía). Así que, concluyendo, luego de dividir los pueblos desde los que no creen en dioses hasta los que creen en uno solamente, sugiere otra cuatripartición: entre los que se alimentan de carne humana, o de otras carnes y finalmente de frutos de la tierra cultivados. En cuanto al vestido, van desde los que se visten de ropa confeccionada, hasta los que van desnudos, o se pintan o decoran el cuerpo con adornos corporales. En cuanto a la habitación, van desde los cavernícolas o arborícolas, que cambian cada noche su domicilio, a los que llevan una tienda de campaña (en eso se diferencian 'árabes' de 'moros', viviendo estos en ciudades). En el caso del gobierno, los hay que viven sin jefes sino en tiempo de guerra hasta los que admiten monarcas. Al llegar a la economía es cuando me parece que preludia la versión escocesa de la teoría de los cuatro estadios:

Quant au vivre le premier art fut celui de nourrir du bestail qui a esté fort pratiqué et estimé au Peru [...] L'art de filer, de titre la laine, et de faire les draps premieremente pour s'habiller, puis por se parer, fut comme un reietton de l'art de la conduite des tropeaux. L'agriculture vint apres, et premieremente celle qui a soin des grains, puis elle s'amusa aux fruits et aux arbres. L'architecture et le bastiment des maisson premierement de bois, puis de terre, puis de perre et de marbre, dont ceux de Cuzco et de Mexique eurent cognoissance [...] Le compagnon de l'Agriculture c'est le trafic par le moyen duquel nous communicons nostre bien aux autres, et tirons à nous le leur [...] du sel, de la queue, du cacao et de la canelle. Les autres arts et industries vont germant apres de main en main. Les dernieres sont les lettres, et les sciences, principalement speculatives, comme fruits de la paix, de la seurté, de l'oisiveté, et de l'abondance... (1615: 320, cursivas añadidas).

En particular es significativo que esta clasificación cultural de pueblos, culturalmente gradualizados, la hiciese para probar la necesidad de tener varios métodos misionales según el pueblo. A lo cual se adapta este capítulo de D'Avity, tras la clasificación ofrecida, cuando prosigue:

C'est pourquoy l'on ne doit manier l'affaire de la religion d'une mesme façon partout. Parmi les Cannibales devoreurs [...] on doit proceder comme avec des ennemys du genre humaine [...] on le doit render [sic] premierement capables et de raison et d'humanité, puis les intruire en la vertu et en la foi Chrestienne [...] Aristote mesme dit que tels hommes doivent estre pris comme des bestes et 
domptez par forcé [...] // Quelques autres n'ont besoin de force ou de violence pour estre retiré de la Barbarie; mais plustost de conduite et d'addresse [...] La conversión du Nouveau Monde a comencé par les victoires et les armes, et a esté poursuivue avec la predication [...] (1613:321-322).

Pongamos inmediatamente los párrafos de Acosta, ordenados del modo que lo hace D’Avity, para mostrar su estrecho parentesco:

Neque enim de omnibus indorum gentibus eodem modo pronuntiare oportet, nisi graviter errare malimus... Iam vero tertia et extrema classis barbarorum quot hominum nationes, quot huius Novi Orbis regiones teneat, dici non potest... Hunc in primis pertinent quicumque a nostris carybes dicuntur, nihil aliud quam sanguinolentam exercentes... Hoc barbarorum genus Aristoteles attigit (Politica, I, 3), cum ferarum more capi et per vim domari posse scripsit... Hos omnes homines aut vix homines humana docere opportet, ut homines ese discant, tum puerorum more instituere... Hae gentes (humaniores et maxime politicae) ... ad saluten Evangelii non aliter fere vocandae sunt quam olim ad apostolis graeci et romani coeterique Asiae atque Europae populi... ${ }^{36}$.

Reconozco que sería cosa de nunca acabar buscar las frases originales que debieron inspirar a D'Avity, no habiendo cita suya precisa de su fuente, pero resulta que la idea explícita que expresa ('adaptación' proporcional del método misional al nivel cultural de los pueblos a evangelizar) no era muy común en esta época: apenas, que sepamos, el tratado misional de Acosta se atrevía a expresarlas, en su proemio, y son perfectamente reconocibles entre los estudiosos del asunto. Veamos finalmente una frase de D'Avity, copiada por Grimstone que logra recoger una idea especifica de Acosta, planteando que la diferencia cultural observada entre pueblos americanos permitía predecir la secuencia que había ocurrido entre ellos, a lo largo del tiempo:

La cinquiesme sorte de brutalité consiste au gouvernement. Car quelques uns entierement sauvages vivent sans aucunes loix et sans aucuns chefs, tant en temps de paix que de guerre; quelques autres n'ont ni des loix ni chefs en temps de paix, mais seulement aux occurences de guerre; autres en ont en paix et en guerre, et ceux-ci se gouvernent par Republique, comme Tlaxcala et Chiololla [¿Cholula?], ou par Monarchie, qui vie[n]t par election comme elle faisoit en la nouvelle Espagne, ou par sucession comme au Peru. Ceux-la sont Barbares qui

36 Cita en Pereña (1984, pp. 66 y 68). Que traduce así: "No conviene, si no queremos errar gravemente, aplicar unas mismas medidas a todos los pueblos de las Indias... Viniendo ya a la tercera y última clase de bárbaros, es imposible decir el número de pueblos y regiones de este Nuevo Mundo que comprende... A este grupo pertenecen en primer lugar todos aquellos que los nuestros llaman caribes; no ejercen otra profesión que la de derramar sangre... A este tipo de bárbaros alude Aristóteles cuando escribía que se les podía cazar como a bestias y domar por la fuerza... Estos otros pueblos (más humanos y políticos) ... han de ser llamados a la salvación del Evangelio casi a la manera misma como lo fueron en otros tiempos griegos y romanos por los apóstoles, así como los demás pueblos de Asia y Europa". (Idem, pp. 67 y 69). 
se gouvernent selon les deux premiers sortes. Et certainement il faut dire qu'au Nouveau Monde les premiers habitants ont esté au commencement sans forme de gouvernement; mais que peu a peu quelques hommes plus capables ont persuadé a leurs compatriotas de demeurer ensemble, et de le bastir quelques logis premierement de branches des arbres, puis des gros bois, et finalement de terre et de pierre. De cette mutuelle communicaton nasquirent les loix, et les arts qui sont les ornement de la vie humaine (1615: 320-321).

Veamos ahora ese mismo planteamiento -no tan directamente como el otro, frase a frase- de parte del texto de Acosta que señalamos como su origen directo:

Hay conjeturas muy claras que por gran tiempo no tuvieron estos hombres reyes ni república concertada sino que vivían por «behetrías», como agora los floridos y los chiriguanaes y los brasiles; y otras naciones muchas que no tienen ciertos reyes, sino conforme a la ocasión que se ofrece en guerra o paz eligen sus caudillos, como se les antoja. Mas, con el tiempo, algunos hombres que en sus fuerzas y habilidad se aventajaban a los demás comenzaron a señorear y mandar -como antiguamente Nembrot-, y poco a poco creciendo vinieron a fundar los reinos de Pirú y de México que nuestros españoles hallaron: que, aunque eran bárbaros, pero hacían grandísima ventaja a los demás indios. (2008: 42-b).

Desta suerte se gobierna la mayor parte deste Nuevo Orbe, donde no hay reinos fundados ni repúblicas establecidas ni príncipes o reyes perpetuos y conocidos, aunque hay algunos señores y principales que son como caballeros, aventajados al vulgo de los demás. Desta suerte pasa en toda la tierra de Chile, donde tantos años se han sustentado contra españoles los araucanos y los de Tucapel, y otros. Así fue todo lo del Nuevo Reino de Granada, y lo de Guatemala y las islas, y toda la Florida y el Brasil, y Luzón y otras tierras grandísimas; excepto que en muchas dellas es aún mayor el barbarismo, porque apenas conocen cabeza sino todos de común mandan y gobiernan, donde todo es antojo y violencia y sinrazón y desorden, y el que más puede ése prevalece y manda. (2008: 212-a, VI:11).

Creo que no hemos hecho el debido caso, hasta ahora, a esta 'enciclopedia moral' de D'Avity/ Grimstone a la hora de estudiar el proceso gradual como se conformó una historia conjetural de la evolución cultural, característico de la Ilustración. Por este medio gradual - del mismo modo que se dio gradualmente la historia social, según el esquema conjetural evolucionista- se ha 'ensayado' que los datos nuevos del pasado de sociedades menos evolucionadas del Nuevo Mundo sirviesen para 'rellenar' los vanos informativos sobre el pasado de nuestras propias sociedades. Los datos aislados, recogidos por diversos soldados y colonos en el Nuevo Mundo, sirvieron para 'reconstruir' el pasado de las sociedades americanas, cuyo presente controlamos etnográficamente. 
Pero son las reflexiones de algunos letrados especialmente dotados, usando los datos etnográficos a su disposición (propios o ajenos), los que permitirán 'reconstruir' el proceso como se ha establecido nuestra ciencia antropológica y nuestra sociología política. Eso vale para el caso escocés como para el ibérico y francés, que no andan tan alejados como se supone.

\section{Bibliografía:}

Acosta, J., De Natura Novi orbis libri duo, et De promulgando Evangelio apud Bsrbaros siue De procuranda indorum salute libri sex (Salmanticae: apud Gillelmum Foquel, 1589-1588; Colonia, in officina Birckmannica, sumptibus Arnoldi Mylii, 1596).

Acosta, J., De procuranda Indorum salute. Pacificación y colonización por L. Pereña... [et al.]. (Madrid: C.S.I.C., 1984. 1984-87, 2. vols. Corpus Hispanorum de Pace vol. XXIII-XXIV).

Acosta, J., Historia natural y moral de las Indias (Sevilla, Juan de León, 1590).

Acosta, J., Histoire naturelle et moralle des Indes tant orientales qu'occidentales: où il est traicté des choses remarquables du ciel, des elemens ... qui sont propres de ce pays; ensemble des mœurs, ceremonies ... des mesmes Indiens.. Traduite en français par Robert Regnault Cauxois (Paris, 1598).

Acosta, J., The natural and morall historie of the East and West Indies. Intreating of the remarkable things of heaven, of the elements, mettalls, plants and beasts which are proper to that country: together with the manners, ceremonies, lawes, governments, and warres of the Indians. Written in Spanish by the R.F. Ioseph Acosta, and translated into English by E.G. (London, Printed by Val. Sims for Edward Blount ad William Aspley, 1604).

Acosta, J., Historia natural y moral de las Indias. Edición crítica de F. del Pino-Díaz (Madrid/Lima, CSIC/Univerisidad Nacional Mayor de S. Marcos. Colección "De acá y de allá. Fuentes etnográficas", $n^{\circ} 2$, 2008). Online "Fondazione Prospero Intorcetta".

Alden, J. E. and D. C. Landis (Eds.) European Americana: a chronological guide to works printed in Europe relating to the Americas, 1493-1776, New York: Readex Books, John C. Brown Lib., 6 vols., 1980-1988.

Barbu, D., "Idolatry and Religious Diversity: Thinking about the Other in Early Modern Europe", Revue genevoise d'anthropologie et d'histoire des religions, $\mathrm{n}^{\circ} 9$ (2014): pp. 39-50.

Bibliotheca Americana. Catalogue of the John Carter Brown Library in Brown University, Providence, Rhode Island. 7 volumes. Millwood: Kraus Reprint Co., 1975.

Broc, N., La géographie de la Renaissance (1420-1620). Paris, Bibliothèque Nationale, Les Éditions du Comité des travaux historiques et scientifiques, 1986.

Corcelles, D. de, "La conquête d'un savoir raisonnable: l'Histoire naturelle et moralle des Indes, tant orientalles qu'occidentalles du P. jésuite José Acosta, 1598”. Dans Le savoir au XVIIe siècle, Actes du 34e congrès annuel de la North American Society for Seventeenth-Century French Literature, sous la direction de John D. Lyons et Cara Welch, Tübingen, Gunter Narr Verlag, 2003, p. 311-321. 
D’Avity, P. Les estats, empires, et principavtez dv mode, representez par la description des pays, moeurs des habitans, richesses des prouinces, les forces, le gounernement, la religion, et les princes qui ont gouuerné chacun estat, auec l'origine de toutes les religions, et de tous les cheualiers et ordres militaires. Par le sr. D.T.V.Y. [pseudonyme] gentilhomme ord[inai]re de la chambre du roy, À S. Omer: Chez Charles Boscard, imprimeur, 1613 y 1614.

D'Avity, P., The Estates, Empires, \& Principalities of the World, Represented by ye description of Countries, maners of Inhabitants, Riches of Provinces, forces, Government, Religion and the Princes That Have Foverned in Every Estate. With the Beginning of All Militarie and Religious Orders... Translated from the French by Edward Grimstone. (London: Printed by Adam Islip for Mathewe Lownes and John Bill, 1615).

del Pino Díaz, F., "Historia de la Antropología en España: Opiniones y proposiciones en relación a las crónicas americanas", Tesis doctoral de la Facultad de Ciencias Políticas y Sociología (Madrid, abril de 1975).

del Pino Díaz, F., "Contribución del Padre Acosta a la constitución de la Etnología. Su evolucionismo". Revista de Indias, vol. XXXVIII, nº 153-154 (1978.), pp. 50746. Madrid, CSIC. (reproducido con modificaciones en Bérose - Encyclopédie internationale des histoires de l'anthropologie, Paris.

URL stable - Handle: 10670/1.kb2870| URL Bérose : article1750.html)

del Pino Díaz, F., "El nacionalismo en la historia de la ciencia: el caso de la Etnología", Ethnica. Revista de Antropología, 12: 97-125. (Barcelona, 1976)

del Pino Díaz, F., "Repercusiones de la nueva historiografía de las ciencias en el caso de la Etnología: el problema de la profesionalización". Alcaveras. Revista de Antropología, 4 (Diciembre, 1984): pp. 19-22.

del Pino Díaz, F., "The Trace of José de Acosta in the Scottish Enlightenment Thinkers (W. Robertson)". Ed. Brill, Leiden, Boston, 2022, en un monográfico titulado "Projections of Jesuit Spanish Scholasticism on British and American Thought”, coord. por José Luis Cendejas Bueno y José Luis Cendejas Bueno.

Gliozzi, G., Adamo e il Nuovo Mondo. La nascita dell'antropologia come ideologia coloniale: dalle genealogie bibliche alle teorie razziali (1500-1700), Firenze: La Nuova Italia, 1977. (Existe una versión francesa de 2000, Theetete Eds.)

Gregoire, V., Imperialisme et cosmopolitisme. Théories de l'Etat et problèmes coloniaux (XVIe-XVIIIe siècle). Paris: Honoré Champion Éditeur, 2017 (Thèse pour obtenir le grade de docteur de L'Université_Paris-Sorbonne, le 01 décembre 2011).

Grimm, M. H. "Historical Precedents and Early Modern Interpretations: English Histories of America, 1500-1700" (Undergraduate Honors Theses. Paper 234. College of William and Mary, Virginia, 2015).

Hakluyt, R., The Principal Navigations, Voiages, Traffiques and Discoueries of the English Nation, Made by Sea or Overland to the remote and farthest distant quarters of the earth, at any time within the compasse of these 1600 years: diuided into three seuerall volumes, according to the positions of the regions .... (London: Imprinted by George Bishop and Ralph Newberie... 3 vols., 1588, 1599, 1600).

Hart, J. H., Representing the New World: the English and French uses of the example of Spain, 1492-1713. (Cambridge Univ. Press, 1997) 
Hont, I., "The language of sociability and commerce: Samuel Pufendorf and the theoretical foundations of the "Four-Stages Theory"' (en A. Pagden (Ed.) The Languages of Political Theory in Early-Modern Europe, Cambridge University Press, 1987: pp. 253-276).

Lafitau, J. F., Mours des sauvages amériquains, comparées aux mœurs des premiers temps, Paris, Saugrain et Hochereau, 1724, 2 vols. in- $4^{\circ}$ (también in $12^{\circ}$ )

Locke, J., [segundo] Ensayo sobre el Gobierno Civil (Madrid: Aguilar, S. A. de Eds., 1977, $2^{\mathrm{a}}$ impr.)

López Sastre, G., "William Robertson y la conquista española de América. Causalidad histórica y ausencia de leyenda negra" (en $\mathrm{M}^{\mathrm{a}}$ J. Villaverde y F. Castilla, dirs., La sombra de la leyenda negra, Madrid, Tecnos, 2016. pp. 291-325).

Meek, R., Social Science and the ignoble savage. (Cambridge Univ. Press, 1976).

(Trad. Los orígenes de la ciencia social: El desarrollo de la teoría de los cuatro estadios. Madrid, Siglo XXI de España Editores, 1981).

O’Malley, J. W. (S. J.), Los primeros jesuitas. Bilbao, Ed. Sal Terrae, 1995 (traducción del original de 1983 en Harvard University Press).

Pagden, A., The fall of natural man. The American Indian and the Origins of Comparative Ethnology. Cambridge U. Press, Cambridge Iberian and Latin American Studies, 1982 y $1986^{2}$. (Trad. en Madrid, Alianza América, 1988).

Purchas, S., Hakluytus Posthumus: or, Purchas His Pilgrimes: Contayning a History of the World in Sea Voyages and Lande Travells by Englishmen and Others. London: For Henry Fetherston, 1625, 4 vols.

Roberston, W., The Works of William Robertson, D.D. To which is Prefixed, An Account of the Life and Writings of the Author, by Dugald Stewart. In Eight volumes (London: T. Cadell, 1840).

---- Historia de la América, Traducción hecha con todo esmero y exactitud aumentada con los libros IX y X. (En Obras escogidas de W. Robertson, Barcelona, Por la casa J. Oliveres Gavarró, 1840, 4 vols.)

Rossini, G., "The criticism of rhetorical historiography and the ideal of scientific method: history, nature and science in the political language of Thomas Hobbes" (en A. Pagden, Ed., The Languages of Political Theory in Early-Modern Europe, Cambridge University Press, 1987: pp. 303-324).

Varella, A. C., "A queda do homem civil: os antigos mexicanos e peruanos na History of America de William Robertson", História Unisinos, 18 (Universidade do Vale do Rio dos Sinos, Brasil, 2014, 2:248-259). 